\title{
The Influence Of Saving Product Attributes And Quality Of Service On Bank Customer Satisfaction
}

\author{
Cholifah dan Agus Sukoco \\ Program Study Manajemen, Fakultas Ekonomi dan Bisnis \\ Universitas Narotama Surabaya \\ Email Author: agus.sukoco@narotama.ac.id
}

\begin{abstract}
This study aims to determine the effect of savings products and service quality on customer satisfaction in the workplace. The samples in this study were 100 customers of the PT Bank Jatim Tenggilis Surabaya Branch Office. Data collection techniques in this study were observation, questionnaires, and librarian studies. While the data analysis technique used is the classical assumption test technique, multiple linear regression analysis, and hypothesis testing using SPSS 17 software. The results show that there is an influence between savings products and services on customer satisfaction. There is a positive and significant influence between savings products and services on customer satisfaction, so the hypothesis is accepted. The coefficient of determination is 0.443 which indicates that the savings products and services together can explain the customer satisfaction of the PT Bank Jatim Tenggilis Surabaya Sub-Branch Office by $44.3 \%$, while the rest is influenced by other variables not examined. There is a relationship between savings products and services with customer satisfaction, so companies must pay more attention to the service products sold and the services provided to create customer satisfaction.
\end{abstract}

\section{Keyword:}

Savings products, services, customer satisfaction.

\section{Pendahuluan}

Bank Jatim adalah satu usaha jasa keuangan dengan bentuk Perseroan Terbatas. Perusahaan ini berusaha memberikan pelayanan terbaik dengan menyediakan produk perbankan dan layanan yang kompetitif. Sebagai satu perusahaan yang bergerak pada bidang jasa keuangan, perusahaan menyadari betapa pentingnya memberikan kepuasan nasabah melalui produk dan pelayanan yang diberikan. Perusahaan ini memiliki visi dan misi untuk menjadi penyedia jasa keuangan nomor satu sebab perusahaan ini menjadi tujuan harapan untuk membangun perekonomian di daerahnya sendiri. Karena menurut Biro Riset Info Bank ada sepuluh BPD yang bermodal sendiri tergolong besar yaitu Bank : Jabar, Jatim, Jateng, Sumut, Riau, DKI, Kaltim, Bali, Sulsel, dan Papua (Info Bank, Februari 2004). Bank Jatim memiliki modal sebesar \$94.245 (Ribuan) (Bank Scope-Bureau van Dijik dan Biro Riset Info Bank, Oktober 2006). Bank Jatim terus menerus mengembangkan kinerja pelayanan, sehingga tidak mudah bank pesaing merebut nasabah Bank Jatim.

Produk dan pelayanan yang baik merupakan impian setiap konsumen. Pada dasarnya produk dan pelayanan yang baik merupakan hasil koordinasi antara perusahaan dan sumber daya manusia di dalamnya yang dituntut harus terus dapat mengembangkan produk dan meningkatkan pelayanan untuk menjaga loyalitas serta meningkatkan kepuasan konsumen. Terlebih untuk usaha jasa keuangan, perusahaan harus dapat memutar pikiran dan kreativitas untuk terus mengembangkan produk dan mengungguli pesaing.

Kepuasan nasabah tidak hanya didukung oleh faktor produk saja, namun juga sangat berpengaruh terhadap pelayanan yang diberikan. Pelayanan dan produk yang baik harus dapat diwujudkan perusahaan mengingat banyaknya kompetitor pada wilayah yang sama ataupun di luar wilayah. Dengan mengukur tingkat kepuasan nasabah akan diketahui apakah ada kesenjangan antara kualitas produk dan layanan yang diharapkan dengan kinerja kualitas produk dan layanan dari produk tabungan yang dirasakan oleh nasabah.

Penelitian ini dilakukan untuk mengetahui sejauh mana pengaruh produk tabungan dan pelayanan terhadap kepuasan nasabah PT. Bank Jatim Kantor Cabang Pembantu Tenggilis Surabaya. Hal ini dikarenakan banyaknya perbankan yang ada menawarkan jenis produk tabungan dan layanan yang sejenis dengan produk tabungan dan pelayanan PT. Bank Jatim. 


\section{Tinjauan Pustaka \\ 2.1 Bank}

Menurut UU RI No. 10 Tahun 1998 tanggal 11 November 1998 dalam Kasmir (2012:24) tentang perbankan, yang dimaksud dengan perbankan adalah "badan usaha yang menghimpun dana dari masyarakat dalam bentuk simpanan dan menyalurkannya kepada masyarakat dalam bentuk kredit dan atau bentuk-bentuk lainnya dalam rangka meningkatkan taraf hidup rakyat banyak."

\subsection{Nasabah}

Setiap nasabah tentu sangat mengharapkan kepuasan dari bank manapun ia melakukan transaksi, kepuasan nasabah menjadi salah satu faktor penting untuk diperhatikan oleh perusahaan, karena nasabah/konsumen merupakan target utama suatu perusahaan/badan usaha perbankan. Kepuasan merupakan tingkat perasaan seseorang setelah membandingkan kinerja atau hasil yang dia rasakan dibandingkan dengan harapannya.

Menurut UU RI No. 10 Tahun 1998 tentang perbankan dimuat tentang jenis dan pengertian nasabah, dalam pasal 1 angka 17 disebutkan bahwa "pengertian nasabah yaitu pihak yang menggunakan jasa bank." Menurut kamus perbankan, "nasabah adalah orang atau badan yang mempunyai rekening simpanan atau pinjaman pada bank."

\subsection{Produk}

Untuk perusahaan yang bergerak pada bidang jasa, terkhusus untuk usaha jasa perbankan harus mengetahui dan memahami pasar dengan baik sebab membuat produk jasa yang baik tidaklah mudah. Misalnya, produk dengan atribut berani menawarkan bunga tinggi dalam produk tabungan, akan terdengar lebih menarik di mata nasabah.

Salah satu kunci sukses bank untuk membangun perusahaan adalah produk dan jasa yang ditawarkan oleh bank yang bersangkutan. Bank harus memiliki berbagai produk unggulan dengan variasi yang dapat dipilih sesuai kebutuhan dengan produk bank lain atau kompetitor, sehingga ia memiliki keunggulan komparatif dibandingkan bank lainnya. Jasa adalah produk yang popular setelah barang, dimana jasa memiliki karakteristik yang berbeda dengan barang.

Menurut Kotler (2008:107), terdapat beberapa faktor utama yang menjadi penentu mutu jasa, yaitu: 1) Akses 2) Komunikasi 3) Kompetensi 4) Kesopanan 5) Kredibilitas 6) Reliabilitas 7) Cepat tanggap 8) Kepastian 9) Hal-hal yang berwujud 10) Memahami/mengenal konsumen.

\subsection{Pelayanan}

Pelayanan merupakan suatu kegiatan yang diberikan produsen kepada konsumen atau perusahaaan/instansi kepada publik untuk memberi rasa puas dan menanggapi respon konsumen.

Menurut Ivancerizh, dkk. dalam Ratminto (2008:2) "pelayanan adalah produk-produk yang tidak kasat mata (tidak dapat diraba) yang melibatkan usaha usaha manusia dan menggunakan peralatan." Menurut Kotler dalam Moeljono (2008:47) bahwa "pelayanan adalah aktivitas atau hasil yang dapat ditawarkan oleh sebuah lembaga kepada pihak lain yang biasanya tdiak kasat mata, dan hasilnya tidak dapat dimiliki oleh pihak lain tersebut."

Menurut Majid (2009:49) bahwa "Pelayanan sangat berpengaruh signifikan terhadap kepuasan pelanggan, namun pelayanan yang baik saja tidak cukup untuk memberi kepuasan pada pelanggan.

Menurut Kasmir (2005:34) terdapat beberapa ciri-ciri pelayanan yang baik yang harus diikuti oleh karyawan yang bertugas melayani pelanggan/nasabah:

1. Tersedianya karyawan yang baik

2. Tersedianya sarana dan prasarana yang baik

3. Bertanggung jawab kepada setiap nasabah sejak awal hingga selesai

4. Mampu melayani secara cepat dan tepat

5. Mampu berkomunikasi

6. Memberikan jaminan kerahasiaan setiap transaksi

7. Memiliki pengetahuan dan kemampuan yang baik

8. Berusaha memahami kebutuhan nasabah i. Mampu memberikan kepercayaan kepada nasabah

\subsection{Kepuasan Nasabah}

Kepuasan konsumen (nasabah) tergantung oleh persepsi, harapan dan pengalaman konsumen (nasabah) selama menggunakan produk atau jasa perusahaan. Dalam mengevaluasi kepuasan terhadap produk, jasa, atau perusahaan tertentu, konsumen umumnya mengacu pada berbagai faktor atau dimensi. Menurut Garvin dalam Tjiptono (2008:25), faktor yang sering digunakan dalam mengevaluasi kepuasan terhadap suatu produk antara lain meliputi: 
1. Kinerja (performance)

2. Ciri-ciri atau keistimewaan tambahan

3. Keandalan (reliability)

4. Kesesuaian dengan spesifikasi (conformance to specifications)

5. Daya tahan (durability)

6. Serviceability

7. Kualitas.

\subsection{Kerangka Konseptual}

Kerangka konsep merupakan sintesa tentang hubungan antar variabel yang disusun dari berbagai teori yang telah dideskripsikan (Sugiyono, $2010: 89$ ).

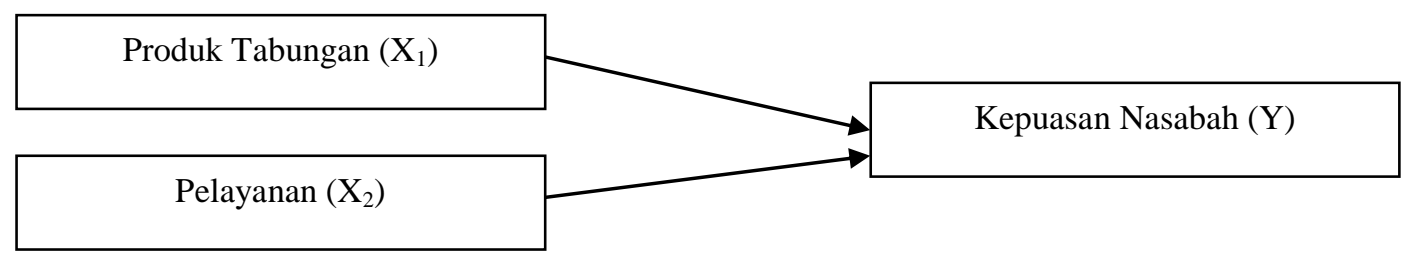

Gambar 1. Kerangka Konseptual Penelitian

Hipotesis yang diajukan dalam penelitian ini adalah:

1. Ho1 $=0=$ Tidak terdapat hubungan antara Produk Tabungan (X1) dengan Kepuasan Nasabah (Y)

Ha $1 \neq 0=$ Terdapat hubungan antara Produk Tabungan (X1) dengan Kepuasan Nasabah (Y)

2. $\mathrm{Ho} 2=0=$ Tidak terdapat hubungan antara Pelayanan (X2) dengan Kepuasan Nasabah $(\mathrm{Y})$

$\mathrm{Ha} 2 \neq 0=$ Terdapat hubungan antara Pelayanan (X2) dengan Kepuasan Nasabah (Y)

\section{Metode Penelitian}

\subsection{Pendekatan Penelitian}

Pendekatan penelitian yang digunakan dalam penelitian ini adalah kuantitatif.

\subsection{Populasi dan Sampel}

Menurut Sugiyono (2013:117) Populasi adalah wilayah generalisasi yang terdiri dari atas obyek atau subyek yang mempunyai kualitas dan karakteristik tertentu yang ditetapkan oleh peneliti untuk dipelajari dan kemudian ditarik kesimpulannya. Berdasarkan pada pendapatan tersebut diatas, maka populasi penelitian ini adalah nasabah PT. Bank Jatim Kantor Cabang Pembantu Tenggilis Surabaya.

\subsection{Sampel Penelitian}

Dalam pengambilan sampel, penelitian ini menggunakan rumus Slovin (dalam Riduwan, 2005:65). Dari rumus Slovin tersebut diperoleh sebagai berikut:

$$
\begin{aligned}
& \mathrm{n}=\frac{\mathrm{N}}{\mathrm{N}(\mathrm{d})^{2}+1} \\
& \mathrm{n}=\frac{125}{100(0,05)^{2}+1} \\
& \mathrm{n}=\frac{125}{100(0,0025)+1} \\
& \mathrm{n}=\frac{100}{0,25+1} \\
& \mathrm{n}=
\end{aligned}
$$

Jadi, sampel dalam penelitian ini sebanyak 100 nasabah PT. Bank Jatim Kantor Cabang Pembantu Tenggilis Surabaya 


\subsection{Jenis, Sumber dan Teknik Pengambilan Data}

Jenis data yang digunakan dalam penelitian ini adalah data primer. Data primer yaitu sumber data yang dikumpulkan secara langsung dari obyek yang diteliti.

Teknik pengambilan data yang dipergunakan dalam penelitian ini adalah:

1. Studi Pustaka

2. Observasi

3. Kuesioner, skor diukur dengan menggunakan skala likers, yaitu sebagai berikut: (1) sangat tidak setuju (2) tidak setuju (3) cukup setuju (4) setuju (5) sangat setuju

\subsection{Variabel Penelitian}

Variabel bebas (independent) yaitu Produk Tabungan $\left(\mathrm{X}_{1}\right)$ dan Pelayanan $\left(\mathrm{X}_{2}\right)$

Variabel Terikat (Dependent) yaitu Kepuasan Nasabah (Y).

\subsection{Definisi Operasional Variabel}

\subsubsection{Produk Tabungan $\left(\mathbf{X}_{1}\right)$}

1. Jenis Tabungan

2. Biaya Administrasi

3. Fasilitas Tabungan

4. Setoran Awal

5.

3.6.2 Pelayanan (X2)

1. Bukti langsung (tangibles)

2. Keandalan (reliability)

3. Daya tanggap (responsiveness)

4. Jaminan (assurance)

5. Empati

\subsubsection{Kepuasan Nasabah (Y)}

1. Kualitas Produk

2. Harga

3. Kualitas Pelayanan

4. Faktor Emosional dan Merk

5. Kemudahan Mendapatkan `Produk Jasa

\subsection{Teknik Analisis Data}

Penelitian ini menggunakan metode analisis regresi dan korelasi berganda dengan menggunakan program komputer (software) SPSS versi 17.0 dan Microsoft Excel 2010. Tahap-tahap yang digunakan dalam mengelola data setelah data terkumpul adalah sebagai berikut:

\subsubsection{Uji Validitas dan Reliabilitas}

Dalam penelitian ini metode yang digunakan dalam uji validitas adalah korelasi Rank Spearman. Pengujian reliabilitas untuk menguji kecenderungan atau kepercayaan alat pengukuran dengan diperoleh nilai $r$ dari pengujian reliabilitas yang menunjukan hasil indeks korelasi yang menyatakan ada tidaknya hubungan antara dua belah instrumen. Dalam penelitian ini metode yang digunakan dalam uji reliabilitas adalah Split Half Method (Spearman Brown Correllation).

\subsubsection{Analisis korelasi (Rank Spearman)}

Korelasi Rank Spearman dapat digunakan untuk mengetahui ada dan tidaknya hubungan dua variabel. Korelasi Rank Spearman dapat dirumuskan dengan:

$$
\rho=1-\frac{6 \sum b_{i}{ }^{2}}{n\left(n^{2}-1\right)}
$$

Gambar 2 Analisis Korelasi 
Sumber : (Sugiyono, 2006)

Keterangan:

$\rho=$ korelasi rank spearman

$b_{i}{ }^{2}=$ selisih antara $\mathrm{X}$ dan $\mathrm{Y}$

$\mathrm{n}=$ jumlah sampel yang diambil

\section{Hasil Dan Pembahasan \\ 4.1 Karakteristik Responden}

Tabel 1 Berdasarkan Jenis Kelamin

\begin{tabular}{ccc}
\hline Jenis Kelamin & Jumlah & $\%$ \\
\hline Pria & 43 & 43 \\
Wanita & 57 & 57 \\
Total & 100 & 100 \\
\hline
\end{tabular}

Sumber : Hasil Data Penelitian, 2016 (diolah)

Dari Tabel 1 diatas terlihat bahwa umumnya nasabah PT. Bank Jatim Kantor Cabang Pembantu Tenggilis Surabaya terbanyak adalah berjenis kelamin pria sebesar 43 orang dengan prosentase sebesar $43 \%$. Sedangkan sisanya adalah mereka yang berjenis kelamin wanita sebanyak 57 orang dengan prosentase sebesar $57 \%$.

Tabel 2 Berdasarkan Pendidikan

\begin{tabular}{ccc}
\hline Pendidikan & Jumlah & $\%$ \\
\hline SMA & 20 & 20 \\
D3 & 33 & 33 \\
S1 & 41 & 41 \\
S2 & 6 & 6 \\
Total & 100 & 100 \\
\hline
\end{tabular}

Sumber : Hasil Data Penelitian, 2016 (diolah)

Dari Tabel 2 diatas terlihat bahwa umumnya nasabah PT. Bank Jatim Kantor Cabang Pembantu Tenggilis Surabaya terbanyak adalah mereka yang memiliki pendidikan sarjana sebesar 41 orang dengan prosentase sebesar $41 \%$.

Tabel 3 Berdasarkan Umur

\begin{tabular}{ccc}
\hline Umur & Jumlah & $\%$ \\
\hline$<20$ Tahun & 20 & 20 \\
20-40 Tahun & 74 & 74 \\
$>$ 40 Tahun & 6 & 6 \\
Total & 100 & 100 \\
\hline
\end{tabular}

Sumber : Hasil Data Penelitian, 2016 (diolah)

Dari Tabel 3 diatas terlihat bahwa umumnya nasabah PT. Bank Jatim Kantor Cabang Pembantu Tenggilis Surabaya terbanyak adalah mereka yang memiliki Umur 20-40 Tahun sebesar 74 orang dengan prosentase sebesar $74 \%$. Banyaknya nasabah yang memiliki Umur $<20$ Tahun sebesar 20 orang dengan prosentase sebesar $20 \%$. Sedangkan yang berusia $>40$ Tahun sebesar 6 orang dengan prosentase sebesar $6 \%$. 


\subsection{Deskriptif Tanggapan Responden}

Tabel 4 Produk Tabungan

\begin{tabular}{clc}
\hline & \multicolumn{1}{c}{ Pernyataan } & Mean \\
\hline No & \multicolumn{1}{c}{ Suku bunga tabungan yang diberikan cukup besar } \\
2 & Suku bunga tabungan lebih besar dibandingkan bank lain (lebih menguntungkan) & 4.1 \\
3 & Biaya administrasi tabungan ringan & 4.8 \\
4 & Bank menanggung biaya kerusakan dan kehilangan buku tabungan & 3.7 \\
5 & Tabungan telah dilengkapi dengan asuransi jiwa yang menguntungkan nasabah & 4.3 \\
6 & Banyak hadiah menarik yang diundi secara berkala & 4.1 \\
7 & Bank Jatim menyediakan fasilitas yang cukup baik untuk memudahkan nasabah & 4.5 \\
& dalam bertransaksi & 4.6 \\
8 & Setoran awal pembukaan tabungan cukup ringan & 4.0 \\
\hline & Setoran awal pembukaan tabungan lebih ringan daripada bank lainnya & 4.0 \\
\hline
\end{tabular}

Sumber : Hasil Data Penelitian, 2016 (diolah)

Berdasarkan pada Tabel 4 di atas nilai total skor diperoleh dari banyaknya frekuensi dikalikan dengan nilai interval, keseluruhan dari nilai tiap frekuensi dijumlahkan. Rata-rata tanggapan responden tentang produk tabungan yang ada di PT. Bank Jatim Kantor Cabang Pembantu Tenggilis Surabaya menyatakan memuaskan atas semua aspek produk tabungan.

Tabel 5. Pelayanan

\begin{tabular}{clc}
\hline No & \multicolumn{1}{c}{ Pernyataan } & Mean \\
\hline 1 & Memiliki fasilitas yang lengkap dan nyaman bagi nasabah & 4.0 \\
2 & Karyawan berpenampilan rapi ,ramah dan sopan & 4.3 \\
3 & Bank Jatim menyediakan brosur dan poster dengan cukup banyak & 4.6 \\
4 & Layanan bank Jatim berjalan dengan baik & 3.6 \\
5 & Pegawai memiliki kompetensi yg baik tentang produk tabungan & 3.8 \\
6 & Pelayanan transaksi tabungan dilakukan dengan cepat & 3.2 \\
7 & Karyawan bank memberikan pelayanan secara cepat kepada nasabah & 4.5 \\
8 & Karyawan bank selalu bersedia untuk membantu ketika kesulitan & 4.6 \\
9 & Sikap karyawan Bank professional dan membuat anda yakin dengan kualitas & 4.1 \\
& pelayanan yang diberikan & 4.2 \\
10 & Pegawai bank jatim melayani sesuai jam kantor & 4.3 \\
11 & Pegawai bank jatim memberikan pelayanan diluar jam kantor sesuai kebutuhan & 4.5 \\
& nasabah. & 4.4 \\
12 & Bank memberikan perhatian khusus secara pribadi & 4.5 \\
13 & Bank merespon setiap tanggapan nasabah & 4.2 \\
\hline
\end{tabular}

Sumber : Hasil Data Penelitian, 2016 (diolah)

Berdasarkan pada Tabel 5 di atas dapat diketahui rata-rata tanggapan responden berkaitan dengan pelayanan dari PT. Bank Jatim Kantor Cabang Pembantu Tenggilis Surabaya menyatakan puas atas semua aspek pelayanan. 
Tabel 6 Kepuasan Nasabah

\begin{tabular}{clc}
\hline No & \multicolumn{1}{c}{ Pernyataan } & Mean \\
\hline 1 & Produk tabungan yang didapat dan dirasakan sudah baik dan berkualitas & 4.4 \\
2 & Produk tabungan Bank Jatim lebih baik dibandingkan bank lainnya & 4.5 \\
3 & Semua harga/biaya di dalam produk tabungan murah dan ringan & 4.4 \\
4 & Semua harga/biaya di dalam produk tabungan tidak memberatkan nasabah & 3.8 \\
5 & Pelayanan yang diberikan sudah cukup baik dan memuaskan & 3.6 \\
6 & Pelayanan diberikan dengan cepat dan sesuai prosedur & 4.0 \\
7 & Anda sudah lama menabung di Bank Jatim dan akan tetap setia untuk terus & 3.7 \\
& menabung & 3.6 \\
9 & Bank Jatim pantas untuk direkomendasikan kepada orang lain/kerabat anda & 4.4 \\
10 & Bank Jatim memberikan kemudahan dan kepuasan bagi nasabahnya & 4.5 \\
& Bank Jatim menyediakan banyak ATM yang tersebar di seluruh Jawa Timur & 4.4 \\
11 & dan memudahkan dalam penarikan uang tunai & 4.5 \\
& Segala keluhan/saran/ pertanyaan dapat disampaikan dengan mudah melalui & \multicolumn{1}{c}{ Total } \\
\hline
\end{tabular}

Sumber : Hasil Data Penelitian, 2016 (diolah)

Berdasarkan pada Tabel 6 di atas dapat diketahui rata-rata tanggapan responden berkaitan dengan kepuasan pada PT. Bank Jatim Kantor Cabang Pembantu Tenggilis Surabaya menyatakan puas atas semua aspek kepuasan nasabah.

\subsection{Validitas dan Reliabilitas}

Uji validitas dilakukan untuk memenuhi taraf kesesuaian dan kecepatan alat ukur (instrumen)

Item pertanyaan mengenai dari seluruh variabel 35 item, mempunyai nilai sig < dari $\alpha$ dan sesuai dengan ketentuan yang telah ditetapkan, maka hal ini berarti bahwa seluruh item pertanyaan yang berjumlah 38 item tersebut seluruhnya valid dan dapat digunakan dalam penelitian.

Berdasarkan hasil pengujian reliabilitas di atas dapat diketahui bahwa semua variabel penelitian memiliki nilai cronbach alpha lebih besar dari 0,60. Dengan demikian dapat disimpulkan bahwa data kuesioner yang peneliti gunakan dalam penelitian ini sudah sangat representatif dalam arti kata pengukuran datanya sudah dapat dipercaya (reliabel).

\subsection{Uji Asumsi Klasik}

Tabel 7 Hasil Uji Multikolinearitas

\begin{tabular}{cccc}
\hline & \multirow{2}{*}{ Model } & \multicolumn{2}{c}{ Collinearity Statistics } \\
& & Tolerance & VIF \\
\hline \multirow{2}{*}{1} & $\mathrm{X} 1$ & .565 & 1.771 \\
& $\mathrm{X} 2$ & .565 & 1.771 \\
\hline
\end{tabular}

Sumber : Hasil Data Penelitian, 2016 (diolah)

Berdasarkan Tabel 7 diketahui tidak ada satu variabel independen yang memiliki nilai Variance Inflation Factor (VIF) kurang dari 10 dan tolerance lebih dari 0,1. Hal ini menunjukkan tidak adanya problem multikolinearitas dalam model regresi yang digunakan dalam penelitian. 


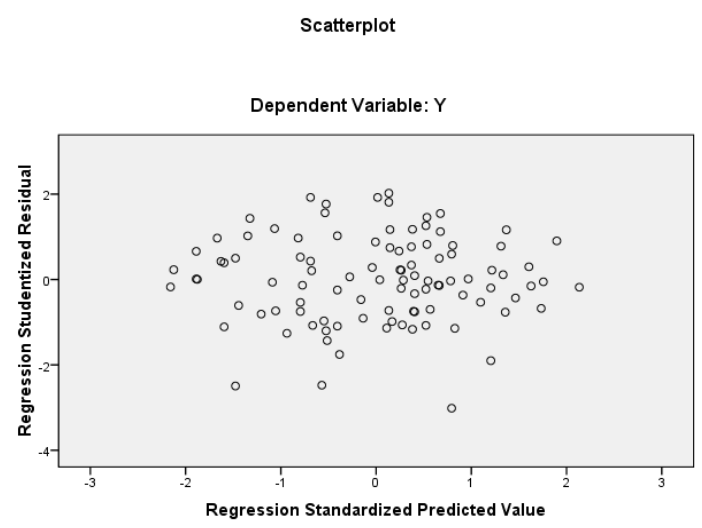

Gambar 3 Hasil Uji Heteroskedastisitas

Sumber : Hasil Data Penelitian, 2016 (diolah)

Dari gambar di atas terlihat titik-titik menyebar secara acak, tidak membentuk sebuah pola tertentu yang jelas, serta tersebar di atas maupun di bawah angka 0 pada sumbu Y, maka dapat disimpulkan bahwa tidak terjadi gangguan heteroskedastisitas pada model regresi. Hal ini menunjukkan bahwa hasil estimasi regresi linier berganda layak digunakan untuk interprestasi dan analisa lebih lanjut.

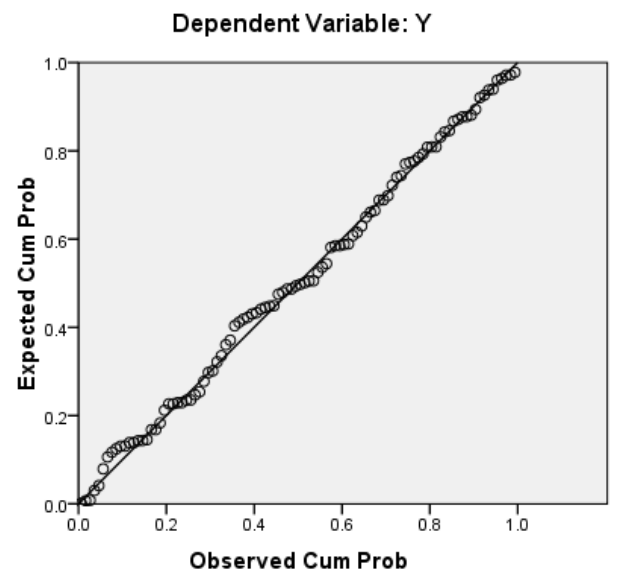

Sumber : Hasil Data Penelitian, 2016 (diolah)

Gambar 4 Hasil Uji Normalitas

Dari gambar di atas terlihat dalam grafik yang dihasilkan jika data menyebar di sekitar garis diagonal dan mengikuti arah garis diagonal, maka model regresi memenuhi asumsi normalitas data.

\subsection{Uji Kelayakan Model}

Tabel 8 Hasil Uji F

\begin{tabular}{clccccc}
\hline & Model & Sum of Squares & Df & Mean Square & F & Sig. \\
\hline \multirow{4}{*}{1} & Regression & 1746.852 & 2 & 873.426 & 38.607 & $.000^{\mathrm{a}}$ \\
& Residual & 2194.458 & 97 & 22.623 & & \\
& Total & 3941.310 & 99 & & & \\
\hline
\end{tabular}

Sumber : Hasil Data Penelitian, 2016 (diolah) 
Berdasarkan Tabel 8 hasil uji kesesuaian model (Goodness of fit) dengan tingkat signifikansi sebesar 0.000 berarti $\alpha<0.05$, maka dapat disimpulkan bahwa layak di teliti.

Tabel 9 Hasil Koefisien Determinasi $\left(\mathrm{R}^{2}\right)$

\begin{tabular}{ccccc}
\hline Model & $\mathrm{R}$ & $\mathrm{R}$ Square & Adjusted R Square & Std. Error of the Estimate \\
\hline 1 & $.666^{\mathrm{a}}$ & .443 & .432 & 4.75639 \\
\hline
\end{tabular}

Sumber : Hasil Data Penelitian, 2016 (diolah)

Berdasarkan Tabel 9 hasil koefisien determinasi $\left(\mathrm{R}^{2}\right)$ nilai $R$ square sebesar 0.443 , hal ini berarti 44,3\% variasi kepuasan nasabah dapat dijelaskan oleh variasi dari ke dua variabel independen, sedangkan sisanya dijelaskan oleh sebab-sebab yang lain diluar variabel yang diteliti.

\subsection{Analisis Regresi Linier Berganda}

$$
\mathrm{Y}=8.846+0.591 \mathrm{X} 1+0,544 \mathrm{X} 2+\mathrm{e}
$$

\subsection{Uji Hipotesis}

\begin{tabular}{lcccc}
\multicolumn{5}{c}{ Tabel 10. Hasil Uji Hipotesis (Uji t) } \\
\hline \multicolumn{1}{c}{ Variabel Bebas } & $\mathrm{t}_{\text {Hitung }}$ & Sig & $(\alpha)$ & Keterangan \\
\hline Produk tabungan (X1) & 3.013 & 0.003 & 0.05 & Berpengaruh Signifikan \\
Pelayanan (X2) & 4.214 & 0.000 & 0.05 & Berpengaruh Signifikan
\end{tabular}

Sumber : Hasil Data Penelitian, 2016 (diolah)

Berdasarkan Tabel 10 hasil uji hipotesis (uji t) menunjukkan bahwa :

1. Variabel Produk tabungan (X1) dengan nilai t sebesar 3.013 dan hasil probabilitas signifikan sebesar $0.003<$ 0.05 , maka $\mathrm{H}_{0}$ ditolak dan $\mathrm{H}_{1}$ diterima. Dengan demikian dapat disimpulkan bahwa variabel Produk tabungan berpengaruh positif signifikan terhadap Kepuasan Nasabah.

2. Variabel Pelayanan (X2) dengan nilai t sebesar 4.214 dan hasil probabilitas signifikan sebesar $0.000<0.05$, maka $\mathrm{H}_{0}$ ditolak dan $\mathrm{H}_{1}$ diterima. Dengan demikian dapat disimpulkan bahwa variabel Pelayanan berpengaruh positif signifikan terhadap Kepuasan Nasabah.

\subsection{Pembahasan}

1. Pengaruh Produk Tabungan terhadap Kepuasan Nasabah.

Berdasarkan hasil pengujian hipotesis yang telah dilakukan diketahui nilai signifikan yang dihasilkan sebesar 0,003 menunujkkan bahwa produk tabungan berpengaruh signifikan terhadap kepuasan nasabah. Nilai koefisien regresi produk tabungan sebesar 0,591 menunjukkan bahwa produk tabungan berpengaruh positif terhadap kepuasan nasabah, atau dengan kata lain semakin baik produk tabungan yang ditawarkan oleh Bank Jatim maka akan semakin menambah kepuasan nasabahnya. PT. Bank Jatim Kantor Cabang Pembantu Tenggilis Surabaya ditentukan oleh seberapa baik kemampuan produk tabungan dalam memenuhi kebutuhan nasabah. Kondisi ini diperkuat dengan perolehan koefisien korelasi berganda sebesar 5,91\% menunjukkan korelasi atau hubungan antara variabel tersebut secara keseluruhan terhadap kepuasan nasabah Bank Jatim Kantor Cabang Pembantu Tenggilis Surabaya Hasil penelitian ini konsisten dengan hasil penelitian yang dilakukan oleh Sari (2013) yang menyatakan bahwa kualitas produk tabungan berpengaruh positif dan signifikan terhadap kepuasan nasabah Bank Nagari Cabang Dharmasraya, dan juga didukung oleh penelitian Rahim (2012) yang menyatakan kualitas produk berpengaruh terhadap kepuasan pelanggan.

2. Pengaruh Pelayanan terhadap Kepuasan Nasabah

Berdasarkan hasil pengujian hipotesis yang telah dilakukan telah dilakukan diketahui nilai signifikansi yang dihasilkan sebesar 0,000 menunjukkan bahwa pelayanan berpengaruh signifikan terhadap kepuasan nasabah. Nilai koefisien regresi layanan sebesar 0,544 menunjukkan bahwa layanan berpengaruh positif terhadap kepuasan nasabah, atau dengan kata lain semakin baik layanan yang diberikan oleh Bank Jatim maka akan semakin menambah kepuasan nasabahnya. Hasil ini mengindikasikan bahwa tingkat kepuasan nasabah PT. Bank Jatim Kantor Cabang Pembantu Tenggilis Surabaya ditentukan oleh seberapa baik kualitas pelayanan 
dalam memenuhi kebutuhan nasabah. Kondisi ini diperkuat dengan perolehan koefisien korelasi berganda sebesar 54,4\% menunjukkan korelasi atau hubungan antara variabel tersebut secara keseluruhan terhadap kepuasan nasabah PT. Bank Jatim Kantor Cabang Pembantu Tenggilis Surabaya memiliki hubungan yang erat.Hasil penelitian ini konsisten dengan hasil penelitian yang dilakukan oleh Prasetianty (2013) yang menyatakan bahwa kualitas pelayanan yang terdiri dari dimensi berwujud, keandalan, daya tanggap, jaminan dan empati berpengaruh positif dan signifikan terhadap kepuasan nasabah. Mendukung penelitian yang dilakukan Prasetyo (2013) yang menyatakan bahwa ada pengaruh positif antara bukti fisik, kehandalan, daya tanggap, jaminan dan empati terhadap kepuasan nasabah.

\section{Penutup}

\subsection{Kesimpulan}

1. Secara simultan produk tabungan dan pelayanan secara serempak adalah positif dan signifikan terhadap kepuasan nasabah pada PT. Bank Jatim Kantor Cabang Pembantu Tenggilis Surabaya

2. Secara parsial variabel produk tabungan dan pelayanan adalah variabel yang signifikan dalam mempengaruhi kepuasan nasabah pada PT. Bank Jatim Kantor Cabang Pembantu Tenggilis Surabaya

3. Dari analisis diperoleh nilai $\left(\mathrm{R}^{2}\right)$ nilai $R$ square sebesar 0.443 berarti $44,3 \%$ variabel kepuasan nasabah dapat dijelaskan oleh produk tabungan dan pelayanan, sedangkan sisanya 53,6\% dapat dijelaskan oleh variabelvariabel lain yang tidak diteliti dalam penelitian ini

\subsection{Saran}

1. Produk juga harus terus dikembangkan dengan melihat perubahan zaman, kebutuhan nasabah, serta mempelajari kelebihan dan kekuatan yang ada pada pesaing, hal ini dibutuhkan agar perusahaan tidak kalah dan dapat terus hidup dan berkembang.

2. Pelayanan yang diberikan harus terus ditingkatkan oleh seluruh pegawai, standar operasional prosedur perusahaan tentang pelayanan harus dilaksanakan pegawai dengan baik untuk dapat menciptakan rasa Kepuasan pada Nasabah.

3. Pimpinan perusahaan beserta stafnya harus berada pada satu kesatuan untuk bekerja sama agar dapat menciptakan kenyamanan, keamanan, serta tercapainya kebutuhan dan keinginan nasabah.

\section{DAFTAR PUSTAKA}

Arikunto, Suharsaimi. 2010. Prosedur Penelitian Suatu Pendekatan Praktik. Yogyakarta: Asdi Mahasatya Irawan, Handi.2009.10 Prinsip Kepuasan Pelanggan.Jakarta:PT. Elex Media Komputindo.

Ismail.2010.Akuntansi Bank.Surabaya:Kencana Prenada Media Group

Juliandi, Azwar. 2013.Metode Penelitian Kuantitatif Untuk Ilmu-Imu Bisnis. Medan:2000

Kasmir.2005.Etika Customer Sevice.Jakarta:Rajawali Pers.

Kasmir . 2012.Bank dan Lembaga Keuangan Lainnya.Jakarta:PT. Raja Grafindo Persada.

Kotler, Philip,2008.Manajemen Pemasaran.Jakarta:Salemba Empat.

Kristianto, Paulus Lilik.2011.Psikologi Pemasaran.Yogyakarta:CAPS.

Majid, Suharto Abdul.2009.Customer Service dalam Bisnis Jasa.Jakarta:PT. Raja Grafindo Persada.

Moeljono, Djokosantoso.2008.Budaya Korporat dan Keunggulan Korporasi. Jakarta:PT. Elex Media Komputindo.

Rangkuti, Freddy.2006.Teknik Mengukur dan strategi Meningkatkan Kepuasan Pelanggan.Jakarta:Pt.Gramedia Pustaka Utama

Ratminto, dan Atik Septi Winarsih.2008. Manajemen Pelayanan. Yogyakarta: Pustaka Pelajar

Santoso, Eko Jalu.2008.The Wisdom Of Business.Jakarta:PT. Elex Media Komputindo

Sugiyono.2008.Metode Penelitian Bisnis. Bandung:Alfabeta

Suharno, Bambang.2006.Langkah Awal Menjadi Enterpreneur Sukses.Jakarta:PT. Media Elex Komputindo

Suharno dan Yudi Sutarso.2009.Marketing in Practice.Surabaya:Graha Ilmu.

Suyatno, Thomas dkk.2007.Kelembagaan Perbankan.Jakarta:PT. Gramedia Pustaka Utama

Tjiptono.2008.Strategi Pemasaran.Yogyakarta:Andi Yogyakarta. 